Research Article

\title{
Ethanol Extract of Sesamum indicum Linn. Inhibits FceRI- Mediated Allergic Reaction via Regulation of Lyn/Syk and Fyn Signaling Pathways in Rat Basophilic Leukemic RBL-2H3 Mast Cells
}

\author{
Hyun Ju Do $\mathbb{D}$, Tae Woo Oh $\mathbb{D}$, and Kwang-Il Park $\mathbb{C}$ \\ Korean Medicine (KM)-Application Center, Korea Institute of Oriental Medicine (KIOM), 70 Cheomdan-ro, Dong-gu, \\ Daegu 41062, Republic of Korea \\ Correspondence should be addressed to Kwang-Il Park; kipark@kiom.re.kr
}

Received 10 January 2019; Revised 12 June 2019; Accepted 7 August 2019; Published 10 October 2019

Academic Editor: Calogero Caruso

Copyright (C) 2019 Hyun Ju Do et al. This is an open access article distributed under the Creative Commons Attribution License, which permits unrestricted use, distribution, and reproduction in any medium, provided the original work is properly cited.

\begin{abstract}
This study is aimed at determining whether Sesamum indicum Linn. beneficially influences FceRI-mediated allergic reactions in RBL-2H3 mast cells; it is also aimed at further investigating Lyn/Fyn and Syk signaling pathways. To examine the antiallergic effect of Sesamum indicum Linn. extract (SIE), we treated antigen/immunoglobulin E- (IgE-) sensitized mast cells with extracts of various concentrations. We examined the degranulation release and concentrations of inflammatory mediators. Additionally, the expressions of genes involved in the FcERI and arachidonate signaling pathways were examined. SIE inhibited the degranulation and secretion of inflammatory mediators in antigen/IgE-sensitized mast cells. SIE reduced the expressions of FceRI signaling-related genes, such as Syk, Lyn, and Fyn, and the phosphorylation of extracellular signal-regulated kinase in antigen/IgE-sensitized mast cells. Additionally, in late allergic responses, SIE reduced $\mathrm{PGD}_{2}$ release and COX-2 and cPLA2 phosphorylation expression in FceRI-mediated mast cell activation. Lastly, $250-500 \mathrm{mg} / \mathrm{kg}$ SIE significantly attenuated the $\mathrm{Ag} / \mathrm{IgE}$-induced passive cutaneous anaphylaxis (PCA) reaction in mice. The potent effect of SIE on RBL-2H3 mast cell activation indicates that the extract could potentially be used as a novel inhibitor against allergic reactions.
\end{abstract}

\section{Introduction}

Mast cells are widely distributed across the human body and are present in various regions, including the skin, respiratory, and digestive systems [1]. These cells generate a large number of mediators that induce inflammation and immune responses to various external stimuli $[1,2]$. Thus, they are crucial in natural and adaptive immune responses. They also play a critical role in the onset and progress of allergic inflammatory diseases, such as asthma, psoriasis, and arthritis. Mast cells are also important in the progression of allergy and anaphylaxis [3]. RBL-2H3 mast cells exhibit the properties of mucosal mast cells, and their most distinctive type comprises several cellular granules and crystallized chemical mediators [4]. Once allergic antigens are crosslinked with immunoglobulin $\mathrm{E}$ (IgE) that is bound to the high-affinity IgE receptor $(\mathrm{FccRI})$ on the cell surface, histamine and $\beta$-hexosaminidase are released [5], which activates RBL-2H3 cells and causes their degranulation. Thus, RBL$2 \mathrm{H} 3$ cells have been generally used to study IgE-FceRI interaction and signaling pathways, such as the degranulation and binding of IgE to FceRI receptors $[5,6]$. Similarly, we have used RBL-2H3 cells as a model cell line to assess the inhibitory effect of Lyn/Syk and Fyn against FceRI-mediated mast cell activation.

Sesamum indicum Linn. (SI) is one of the most important seed crops and traditional health food in Asian countries. Most pharmacological studies on S. indicum seeds have 
reported hypoglycemic effects in genetic diabetes, antitumor effects, antiestrogenic activity, positive effects on Parkinson's disease patients, antihypertensive effects, and increased vitamin E levels without the use of vitamin E supplements. In addition, aqueous defatted seed extracts from $\mathrm{S}$. indicum have already been demonstrated to exhibit hypoglycemic and hypolipidemic activities. Thus, SI has been shown to have fat-lowering effects in hypercholesterolemic rats; it reduces weight gain caused by cholesterol intake and reinforces the antioxidant defense system in the body [7]. In addition, SI has been reported to inhibit liver damage and oxidative stress in septic mice [8]. SI contains high amounts of plant lignans, including sesamin, sesamolin, and sesaminol glucosides. Sesamin, the major fat-soluble lignan in sesame seeds, influences lipid metabolism and has antihypertensive and anticancer properties $[9,10]$. However, only a limited number of studies have examined antiallergenic properties of extracts from sesame seeds.

The present study investigated the antiallergic activities of the Sesamum indicum Linn. extract (SIE) against FceRImediated allergic reactions in mast cells and the mechanism by which SIE suppresses these allergic reactions. The results of this study would be important in the advancement of plant medicines against allergic diseases.

\section{Material and Methods}

2.1. SIE Preparation. The samples of Sesamum indicum Linn. (SI) were obtained as dried herbs from Yeongcheon Oriental Herbal Market (Yeongcheon, South Korea) and were authenticated by the Korean Medicine Application Center, Korea Institute of Oriental Medicine. SI (50 g) was extracted using $70 \%$ ethanol at $40^{\circ} \mathrm{C}$ for $24 \mathrm{hr}$ in a shaking incubator. Subsequently, the extract was filtered using a $150 \mu \mathrm{m}$ filter paper and concentrated in a rotary vacuum evaporator (Buchi, Tokyo, Japan). Samples were freeze-dried and stored at $-20^{\circ} \mathrm{C}$ before use. Sample acquisition was $5.4 \mathrm{~g}$, and the yield was $18.5 \%$. The lyophilized powder was resuspended in distilled water, centrifuged at $10,000 \times \mathrm{g}$ for $15 \mathrm{~min}$, and filtered through a $0.2 \mu \mathrm{m}$ sterile filter to prepare the SIE. The HPLC analysis method and results are given in Supplementary Materials (available here).

2.2. Cell Culture and Drug Treatment. Rat RBL-2H3 mast cells were cultured in Minimum Essential Medium- $\alpha$ (MEM- $\alpha$ ) containing 10\% heat-inactivated fetal bovine serum (FBS) and $1 \%$ antibiotics $(100,000 \mathrm{U} / \mathrm{L}$ penicillamine and $100 \mathrm{mg} / \mathrm{L}$ streptomycin) at $37^{\circ} \mathrm{C}$ in humidified $5 \% \mathrm{CO}_{2}$ conditions. The cells were seeded onto a 6 -well plate $\left(3 \times 10^{5}\right.$ cells/well $)$ or 96 -well plate $\left(2 \times 10^{4}\right.$ cells/well $)$ for $24 \mathrm{hr}$. At day 2 postconfluence, the medium was changed to MEM- $\alpha$ (10\% FBS and $1 \%$ antibiotics) containing dinitrophenyl (DNP)-IgE $(0.1 \mu \mathrm{g} / \mathrm{mL})$ for $16 \mathrm{hr}$. The medium was replaced with serum-free MEM- $\alpha$ (1\% FBS and $1 \%$ antibiotics). The cells were pretreated with SIE (100, 300, and $500 \mu \mathrm{g} / \mathrm{mL}$ ) or $100 \mathrm{nM}$ dexamethasone before DNPhuman serum albumin $(0.1 \mu \mathrm{g} / \mathrm{mL})$ treatment for $10 \mathrm{~min}$ or $4 \mathrm{hr}$.
2.3. Cell Viability. The RBL-2H3 mast cells were treated with various concentrations of SIE for $1 \mathrm{hr}$. To determine cell cytotoxicity, the cells were incubated with $0.5 \mathrm{mg} / \mathrm{mL}$ of MTT reagent for $40 \mathrm{~min}$ at $37^{\circ} \mathrm{C}$. The medium was discarded, and dimethyl sulfoxide was added to the cells for $5 \mathrm{~min}$. Absorbance readings at $570 \mathrm{~nm}$ were obtained using a microplate reader.

2.4. $\quad N$-Acetyl- $\beta$-d-glucosaminidase $(\beta$-Hexosaminidase) Release Assay. RBL-2H3 mast cells were seeded into a 96well plate and were pretreated with drug. Subsequently, $25 \mu \mathrm{L}$ of 4 -methyl-umbellyferyl- $\mathrm{N}$-acetyl- $\beta$-d-glucosaminidase $(10 \mathrm{mM})$ was added to the supernatant of the sensitized cells with IgE for 1 hour at $37^{\circ} \mathrm{C}$. To stop the reaction, the solution was mixed with sodium carbonate buffer $(0.1 \mathrm{M}$, $\mathrm{pH} 10.0$ ), and the absorbance was measured at $405 \mathrm{~nm}$ on a microplate reader.

2.5. Measurement of Inflammatory Mediators. The cells were pretreated with Sesamum indicum Linn. extract (SIE; 100, 300 , and $500 \mu \mathrm{g} / \mathrm{mL}$ ) or $100 \mathrm{nM}$ dexamethasone before DNP-human serum albumin $(0.1 \mu \mathrm{g} / \mathrm{mL})$ treatment for $4 \mathrm{hr}$. The concentrations of TNF- $\alpha$ (R\&D Systems, MN, USA), IL-4 (eBioscience, CA, USA), IL-6 (Thermo Fisher Scientific, MA, USA), histamine (ENZO, NY, USA), and PGD2 (Cayman, MI, USA) in the cell culture media were measured according to the manufacturer's instructions.

2.6. Immunoblot Analysis. The RBL-2H3 mast cells were sensitized with IgE for $10 \mathrm{~min}$ or $4 \mathrm{hr}$. Total proteins were extracted using RIPA buffer (Merck Millipore, Darmstadt, Germany) containing a protease and phosphatase inhibitor cocktail (Roche, Basel, Switzerland). Proteins were quantified using the bicinchoninic acid assay and were then separated by $10 \%$ sodium dodecyl sulfate polyacrylamide gel electrophoresis and transferred onto an activated polyvinylidene difluoride membrane for $100 \mathrm{~min}$. The blots were blocked with 5\% BSA and incubated with primary antibodies $(1: 1000)$ at $4^{\circ} \mathrm{C}$ overnight and then incubated with horseradish peroxidase-conjugated secondary antibodies for $1 \mathrm{hr}$ at room temperature. Protein expressions were detected using a western blot detection kit (Thermo Fisher Scientific, MA, USA) and ChemiDoc ${ }^{\mathrm{TM}}$ Touch Imaging System (Bio-Rad, CA, USA).

2.7. Animals. Male ICR mice, 5 weeks of age, were randomly assigned to five groups after 1 week adaptation period: control group (CTL, $n=5), \mathrm{Ag} / \mathrm{IgE}$ group (Ag/IgE, $n=5$ ), $\mathrm{Ag} / \mathrm{IgE}$ treated with $10 \mathrm{mg} / \mathrm{kg}$ dexamethasone group (Dex, $n=5$ ), Ag/IgE treated with $250 \mathrm{mg} / \mathrm{kg}$ SIE group (SIE 250, $n=5$ ), and $\mathrm{Ag} / \mathrm{IgE}$ treated with $500 \mathrm{mg} / \mathrm{kg}$ SIE group (SIE $500, n=5)$. SIE was prepared in saline, and CTL and Ag/IgE groups received equivalent volumes of saline. All experiments were approved by the Committee on Animal Experimentation and Ethics of KIOM.

2.8. Passive Cutaneous Anaphylaxis (PCA) in Mice. At day 1, anti-DNP-IgE (4 $\mu \mathrm{g} / \mathrm{mL})$ antibody was subcutaneously injected into the ears of mice. At day 2, IgE-sensitized mice were administered oral SIE (250 or $500 \mathrm{mg} / \mathrm{kg})$ or 


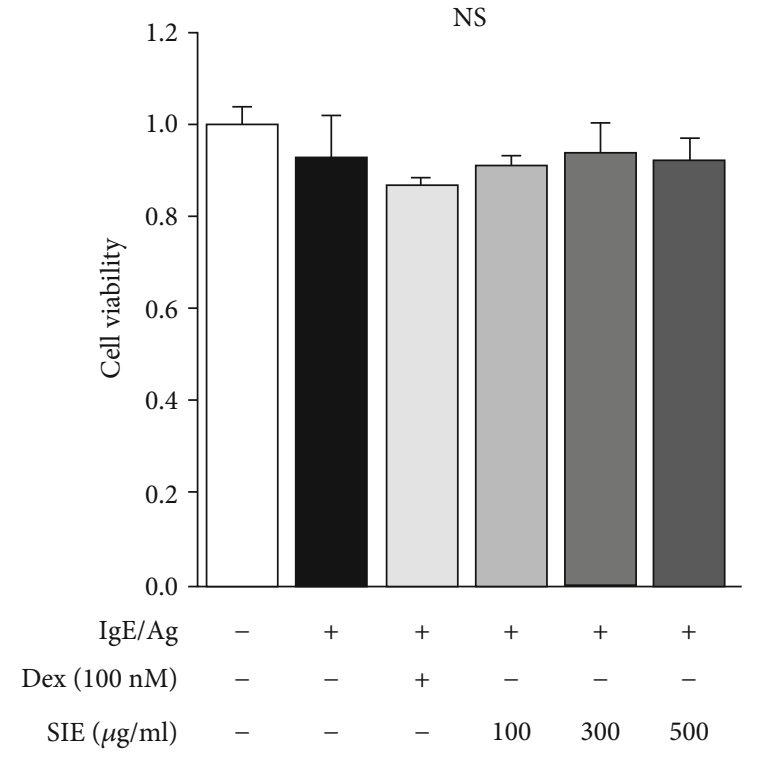

(a)

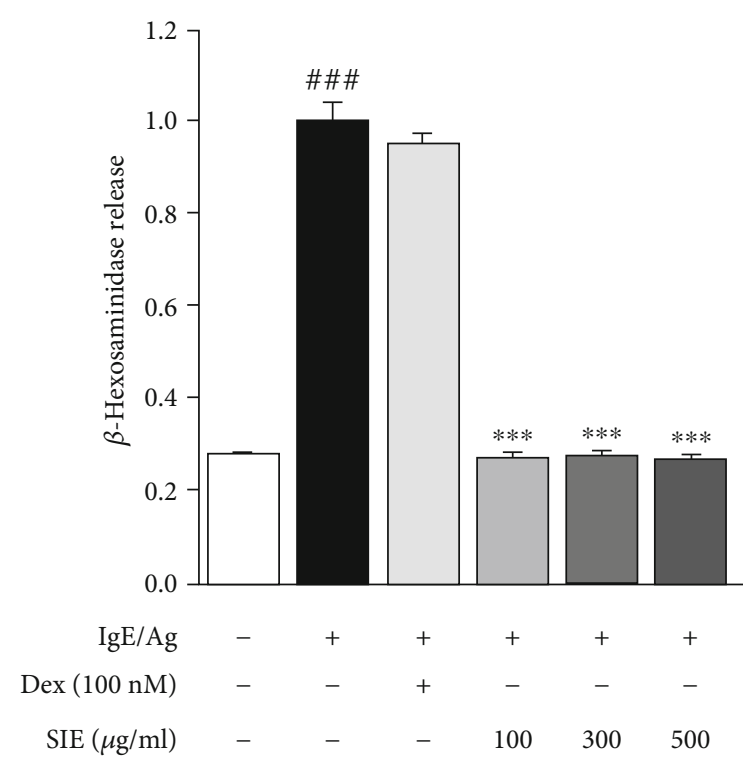

(b)

FIGURE 1: Effects of SIE on (a) cell viability and (b) $\beta$-hexosaminidase release in the RBL-2H3 mast cells. The results are expressed as means \pm S.E. of at least three independent experimental results, tested by analysis of variance using Bonferroni's post hoc test; $\# \#$ \# $<0.0005$ considered as indicative of a significant differences versus the control group and ${ }^{* * *} p<0.0005$ as indicative of significant differences versus the IgE/Ag-treated group. NS: nonsignificant at the 0.05 probability level.

dexamethasone $(10 \mathrm{mg} / \mathrm{kg})$. One hour later, DNP-HSA $(300 \mu \mathrm{g} / \mathrm{mL})$ containing 1\% Evans blue was injected into the tail veins. One hour later, the mice were sacrificed using $\mathrm{CO}_{2}$ and tissues from the treated ears were obtained. The Evans blue dye was removed by the ear tissue, which were then incubated with $0.4 \mathrm{~mL}$ formamide at $63^{\circ} \mathrm{C}$ for $16 \mathrm{hr}$. Absorbance at $620 \mathrm{~nm}$ wavelength was measured using a microplate reader.

2.9. Histology. For histological analysis, ear tissues were fixed in $100 \mathrm{~mL}$ of $4 \%$ paraformaldehyde in $0.1 \mathrm{M}$ phosphate buffer (pH 7.4). $5 \mu \mathrm{m}$ thick sections of the paraffin-embedded ear tissue blocks were cut on a cryoultramicrotome (Leica, Wetzlar, Germany), mounted on positively charged glass slides, and dried in an oven at $60^{\circ} \mathrm{C}$ for $30 \mathrm{~min}$. The sections were deparaffinized in xylene and then rehydrated in graded ethanol and water. Endogenous peroxidase was blocked by incubation in 3\% $(v / v)$ hydrogen peroxide for $10 \mathrm{~min}$. Nonspecific endogenous protein binding was blocked using $1 \%$ bovine serum albumin (BSA). Sections were counterstained with hematoxylin-eosin (H\&E) staining or toluidine blue. The specimens were mounted with Permount (Fisher, Fair Lawn, NJ), and images were captured using a Nikon fluorescence microscope equipped with NIS-Elements BR 4.50 software (Nikon, Tokyo, Japan). Histopathological changes of eosinophils in H\&E-stained tissues and mast cells in toluidine blue-stained tissues were counted in three different parts by blind observed under microscope with 100x and 400x magnification.

2.10. Statistical Analysis. Data were expressed as mean \pm S.E. from three independent experiments. One-way analysis of variance and Bonferroni's post hoc test were used to deter- mine the statistical significance of differences between each treated group and the negative control (IgE group) using the GraphPad Prism software (GraphPad Prism software Inc., version 5.02, La Jolla, CA, USA). ${ }^{*} p<0.05,{ }^{* *} p<0.005$, and ${ }^{* * *} p<0.0005$ were considered statistically significant.

\section{Results}

3.1. Effect of SIE on IgE-Induced Degranulation and Inflammatory Mediators in RBL-2H3 Mast Cells. To determine the cell viability rate of SIE treatment on IgE-induced RBL-2H3 mast cells, we performed the MTT assay and found that SIE did not adversely affect cell viability at concentrations of 100,300 , and $500 \mu \mathrm{g} / \mathrm{mL}$ (Figure $1(\mathrm{a})$ ). $\beta$-Hexosaminidase release as a marker of degranulation in mast cells is used as a good indicator of the degree of allergic reaction [11]. At the initial screening stage, the experiment was conducted using low concentrations $(1-10 \mu \mathrm{g} / \mathrm{mL})$; however, they were not effective. Consequently, we conducted the study using relatively high concentrations $(100-500 \mu \mathrm{g} / \mathrm{mL})$, which are the concentrations that have been applied in previous studies [12]. As shown in Figure 1(b), SIE significantly decreased the $\beta$-hexosaminidase release of mast cells at all doses ranging from 100 to $500 \mu \mathrm{g} / \mathrm{mL}$. SIE treatment decreased the TNF- $\alpha$ and IL- 4 concentrations in the IgEsensitized RBL-2H3 cells in a concentration-dependent manner (Figures 2(a) and 2(b)). Similarly, IL-6 levels were significantly lower in the SIE treatment group than in the Ag/IgE-mediated RBL-2H3 mast cells (Figure 2(c)).

3.2. Effects of SIE on the FceRI Signaling Pathway in RBL-2H3 Mast Cells. As shown in Figure 2(d), SIE inhibited Ag/IgEmediated histamine release on RBL-2H3 mast cells. SIE 


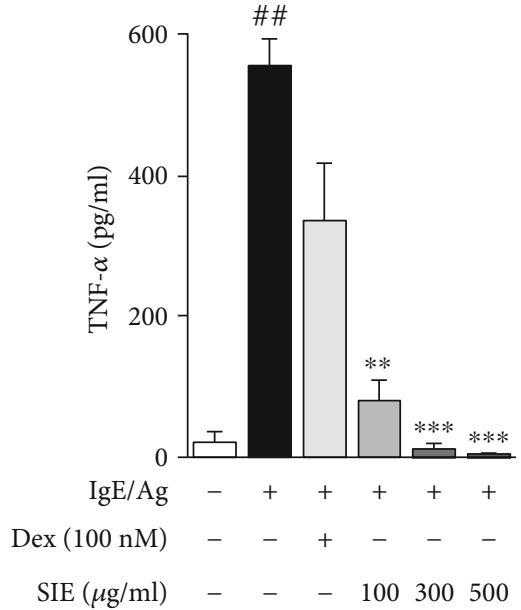

(a)

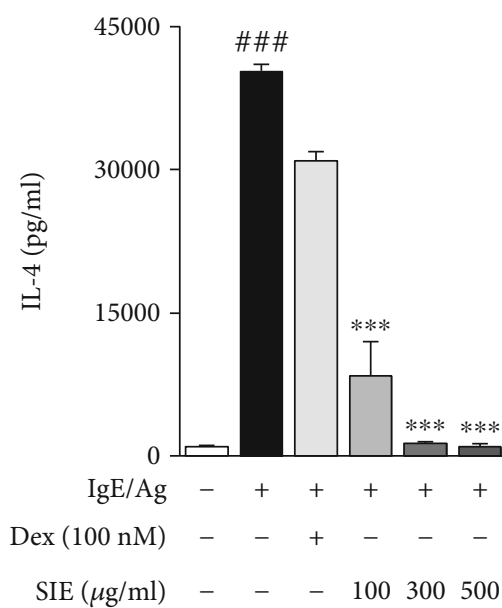

(b)

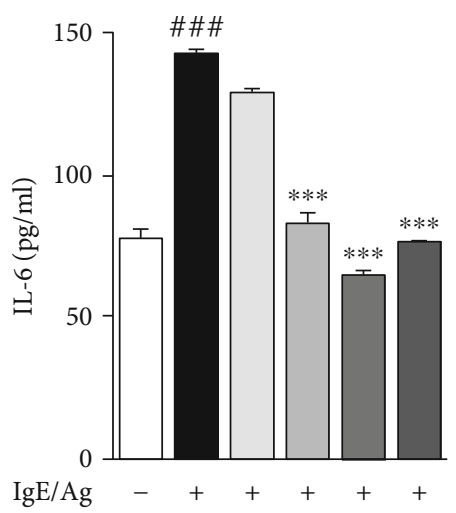

Dex $(100 \mathrm{nM})$

SIE $(\mu \mathrm{g} / \mathrm{ml})$

(c)

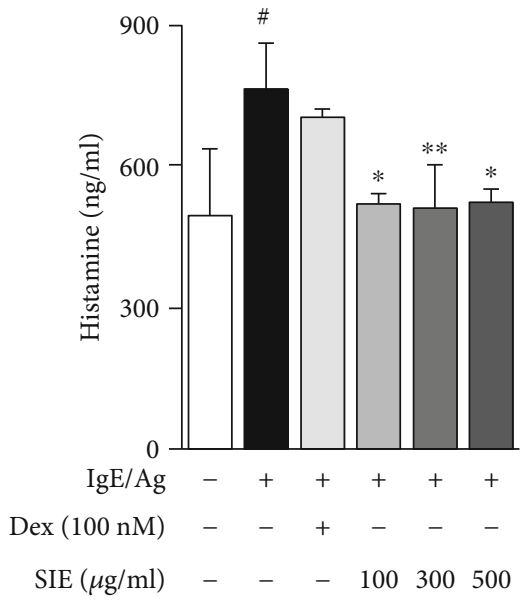

(d)

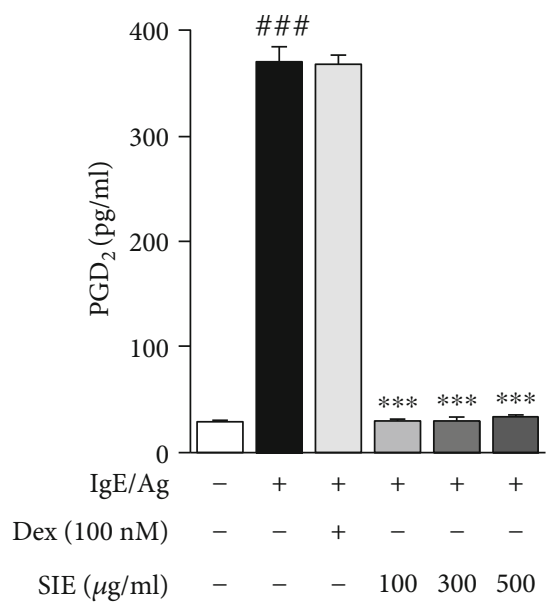

(e)

FIGURE 2: Effects of SIE on proinflammatory cytokines, including (a) TNF- $\alpha$, (b) IL-4, (c) IL-6, (d) histamine, and (e) PGD 2 in the RBL-2H3 mast cells. The results are expressed as means \pm S.E. of at least three independent experimental results, tested by analysis of variance using Bonferroni's post hoc test; ${ }^{\#} p<0.05$, ${ }^{\# \#} p<0.005$, and ${ }^{\# \# \#} p<0.0005$ considered as indicative of a significant differences versus the control group and ${ }^{*} p<0.05,{ }^{* *} p<0.005$, and ${ }^{* * *} p<0.0005$ as indicative of significant differences versus the IgE/Ag-treated group. NS: nonsignificant at the 0.05 probability level.

reduced the phosphorylated level of Lyn and Syk protein in the FceRI signaling cascade. However, SIE had no effect on phosphorylation of Fyn. Additionally, SIE dramatically decreased the phosphorylation of phospholipase $\mathrm{C} \gamma 1$ (PLC $\gamma 1)$, which is involved in the degranulation process of mast cells (Figure 3(a)). Furthermore, SIE markedly reduced the phosphorylation of mitogen-activated protein kinases (MAPKs), such as ERK, JNK, and MEK1/2. The phosphorylation of ERK, JNK, and MEK1/2 was reduced by SIE in a dose-dependent manner. Similarly, AKT and $\operatorname{IkB} \alpha$ phosphorylation was also reduced, which demonstrated that SIE activated the FceRI signaling pathway in Ag/IgE-activated RBL-2H3 cells (Figure 3(b)).

3.3. Effects of SIE on the Arachidonate Signaling Pathway in RBL-2H3 Mast Cells. Next, we observed the effect of SIE on arachidonate cascade activation, such as on the concentration of PGD2 and expressions of COX-2 and p-cPLA2 implicated in FceRI receptor activation [13]. The concentrations of
PGD2 significantly decreased at all concentrations (Figure 2(e)). We tested the antiallergic effects of SIE on the arachidonate signaling pathway, and the activations of COX-2 and p-cPLA2 were examined in Ag/IgE-activated RBL-2H3 mast cells. As shown in Figures 4(a) and 4(b), we observed a decreasing trend in the COX-2 and p-cPLA2 protein levels upon treatment with SIE.

3.4. Effect of SIE on Allergic Responses in the PCA Model. The concentration of Evans blue significantly increased from $3.43 \pm 0.28 \mu \mathrm{g} /$ ear in the CTL group to $16.70 \pm 2.51 \mu \mathrm{g} / \mathrm{ear}$ in the $\mathrm{Ag} / \mathrm{IgE}$ group with the PCA reaction $(p<0.0005)$. Concentrations of Evans blue were significantly lower in the SIE 250 group $(8.33 \pm 0.77 \mu \mathrm{g} / \mathrm{ear}, p<0.0005)$, the SIE 500 group $(5.71 \pm 1.11 \mu \mathrm{g} / \mathrm{ear}, p<0.0005)$, and the Dex group $(6.08 \pm 0.85 \mu \mathrm{g} / \mathrm{ear}, p<0.0005)$ (Figures $5(\mathrm{a})$ and $5(b))$. To evaluate the effect of SIE extract on inflammatory response, we investigated the effects of SIE extract on ear inflammation; histological changes in ear tissues were 

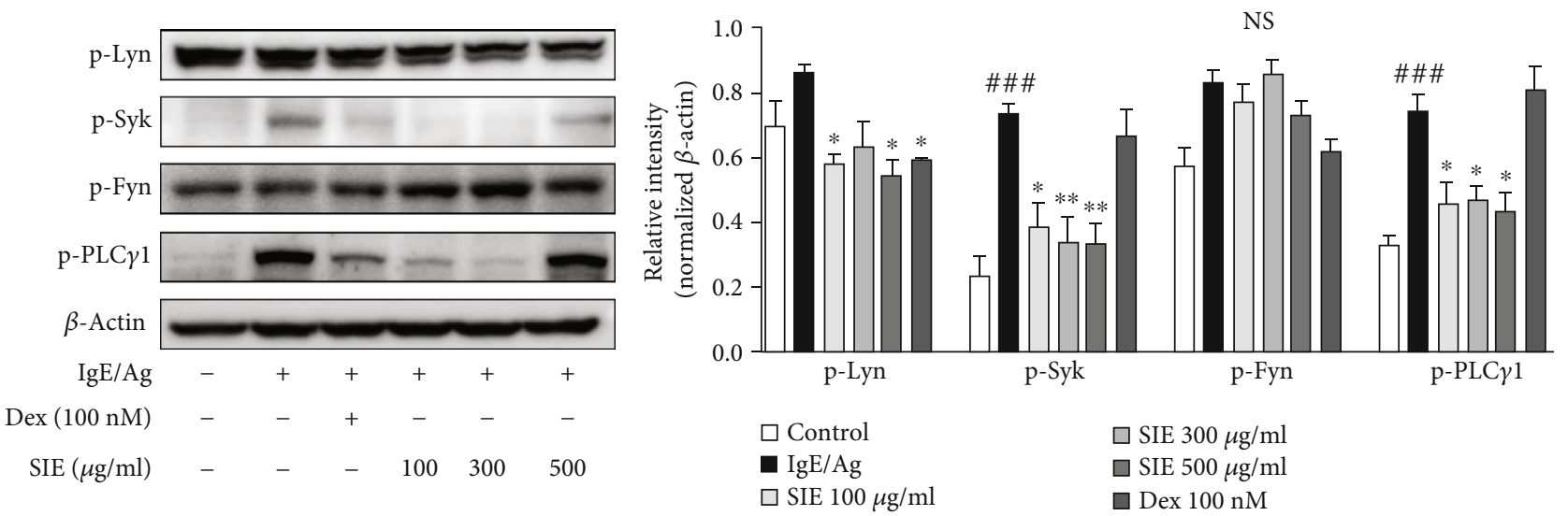

(a)
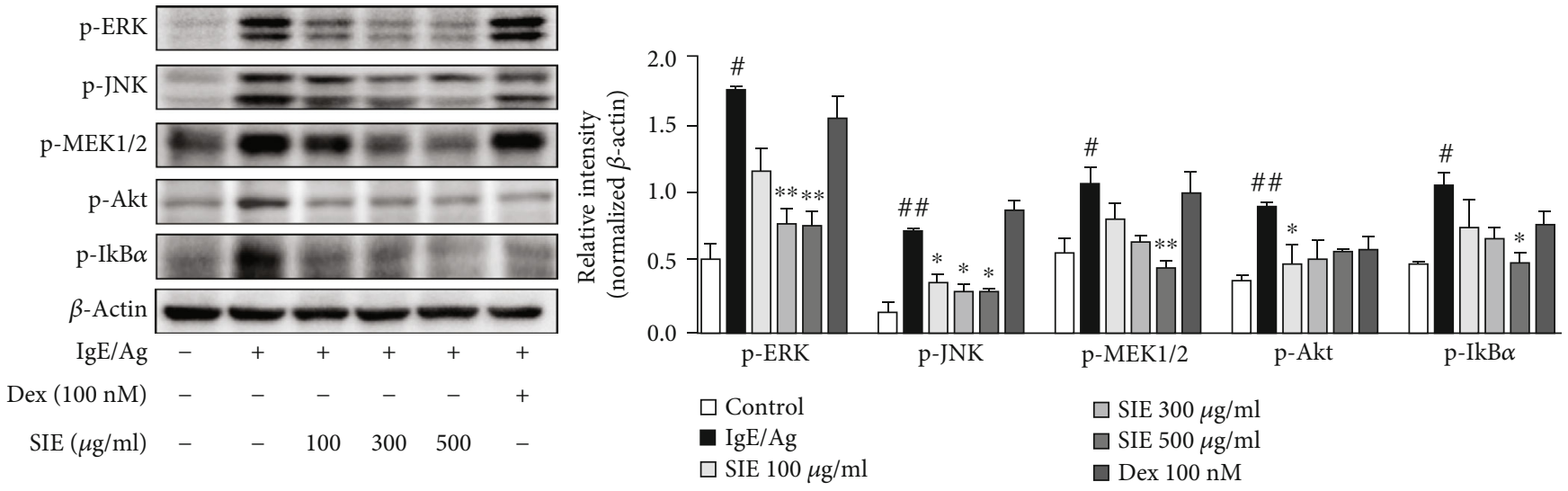

(b)

FIGURE 3: Effects of SIE on the FceRI signaling pathways in RBL-2H3 mast cells. In the FceRI signaling pathway, immunoblot analysis was performed by using (a) anti-p-Syk, p-Lyn, p-Fyn, and p-PLC $\gamma 1$ and (b) p-ERK, p-JNK, p-MEK1/2, p-Akt, and p-IkB $\alpha$ antibodies. Results are expressed as means \pm S.E. of at least five independent experimental results, tested by analysis of variance using Bonferroni's post hoc test; ${ }^{\#} p<0.05$ and ${ }^{\# \# \#} p<0.0005$ considered as indicative of significant differences versus the control group and ${ }^{*} p<0.05,{ }^{* *} p<0.005$, and ${ }^{* * *} p<0.0005$ as indicative of significant differences versus the IgE/Ag-treated group. NS: nonsignificant at the 0.05 probability level.

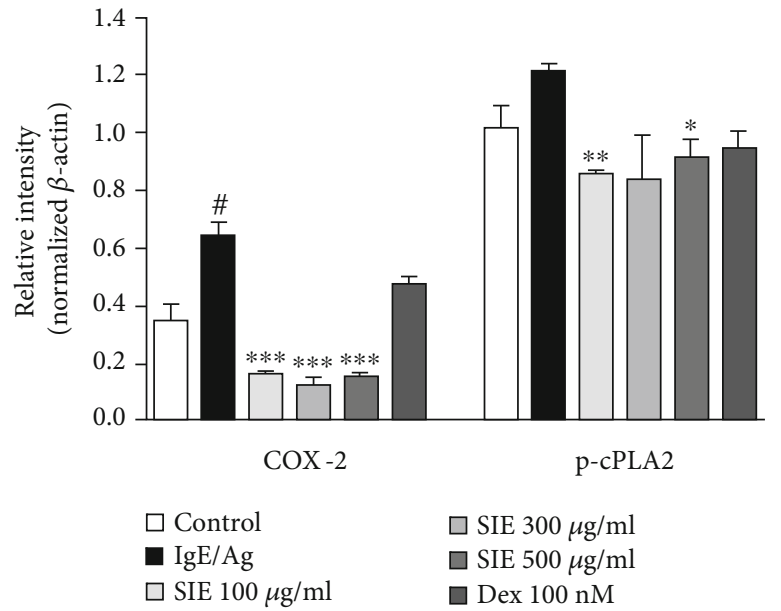

(a)

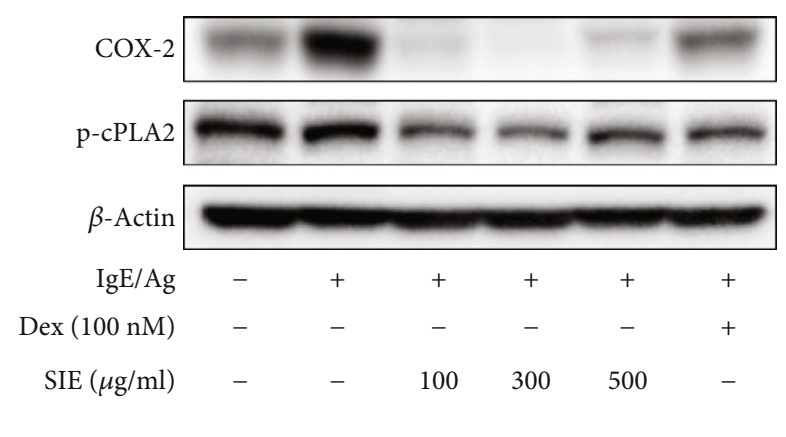

(b)

FIgURE 4: $(a, b)$ Effects of SIE on the arachidonate signaling pathways in the RBL-2H3 mast cells. In the arachidonate signaling pathway, immunoblot analysis was performed by using anti-COX-2 and p-cPLA2 antibodies. $\beta$-Actin was used as a protein loading control. Results are expressed as means \pm S.E. of at least five independent experimental results, tested by analysis of variance using Bonferroni's post hoc test; ${ }^{\#} p<0.05$ considered as indicative of significant differences versus the control group and ${ }^{*} p<0.05,{ }^{* *} p<0.005$, and ${ }^{* * *} p<0.0005$ as indicative of significant differences versus the IgE/Ag-treated group. 

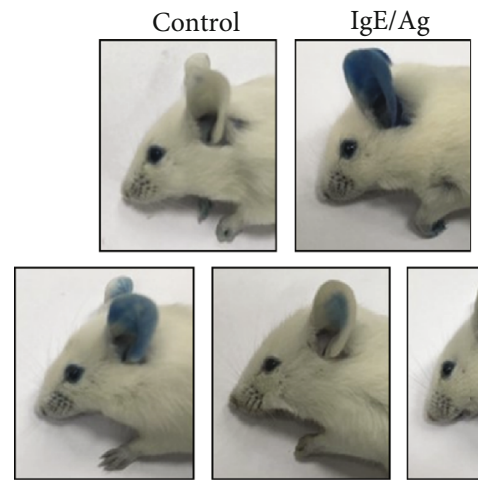

$+\mathrm{SIE} 250 \mathrm{mg} / \mathrm{kg}$

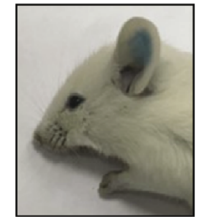

+ SIE $500 \mathrm{mg} / \mathrm{kg}$

(a)

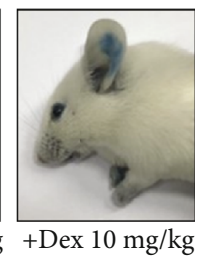

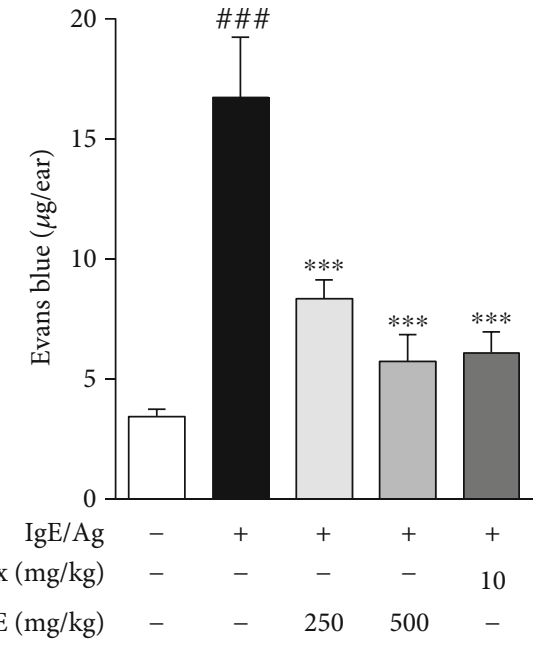

(b)

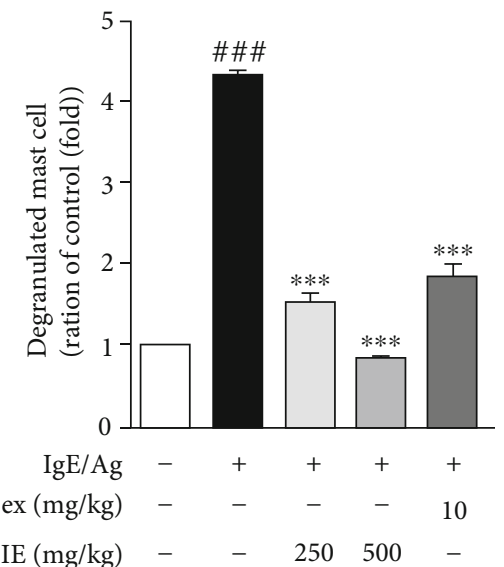

(c)

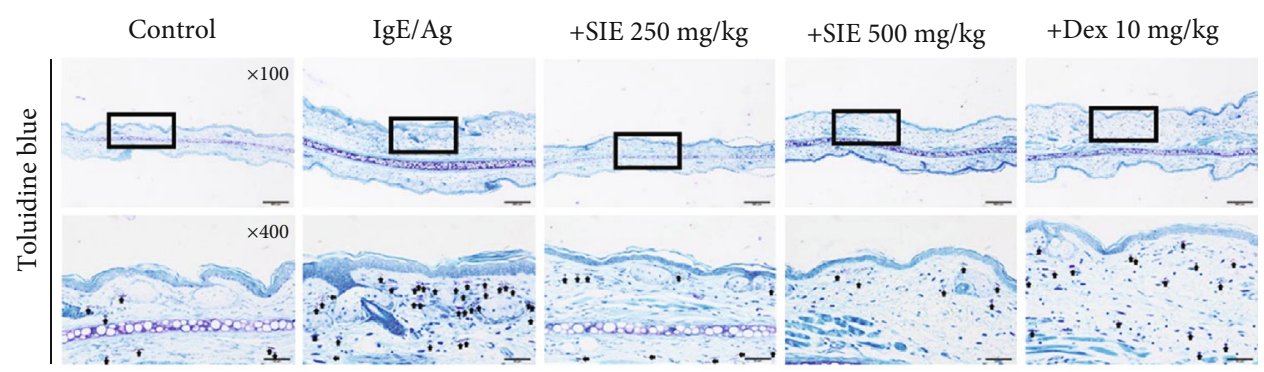

(d)
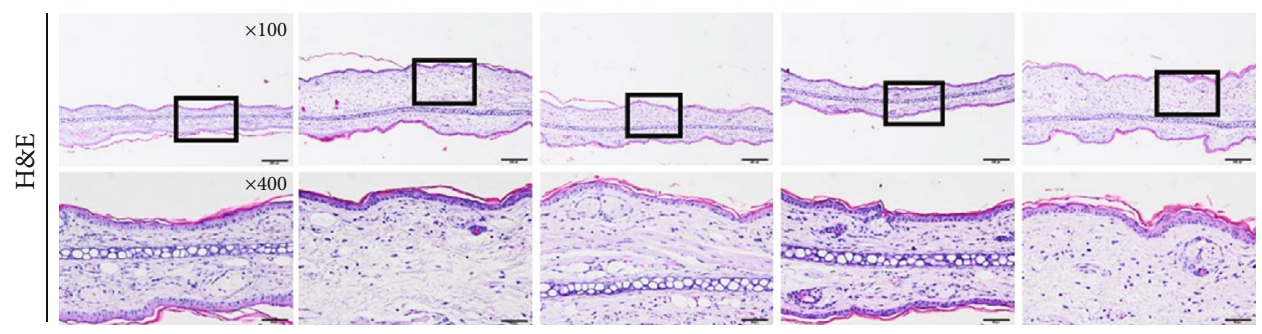

(e)

FIGURE 5: Effect of SIE on the Ag/IgE-induced passive cutaneous anaphylaxis model. ICR mice were intradermally administered DNP-IgE $(4 \mu \mathrm{g} / \mathrm{mL})$ via the ear for $24 \mathrm{hr}$ and were then were orally administered SIE $(250 \mathrm{and} / \mathrm{or} 500 \mathrm{mg} / \mathrm{mL})$ and dexamethasone $(10 \mathrm{mg} / \mathrm{mL})$. One hour later, DNP-HSA $(300 \mu \mathrm{g} / \mathrm{mL})$ containing $1 \%$ Evans blue was intravenously injected into their tail veins for $1 \mathrm{hr}$. (a, b) The extravasated dye in the ears was analyzed using the procedure described in Material and Methods. (c) The average numbers of mast cells per field. Paraffin-embedded skin sections were prepared and stained with (d) toluidine blue and (e) H\&E staining. Bars $=100 \mu \mathrm{m}$. Results are expressed as means \pm S.E. of at least five independent experimental results that were tested by analysis of variance with Bonferroni's post hoc testing; ${ }^{\# \# \#} p<0.0005$ versus the control group; ${ }^{* * *} p<0.0005$ versus the IgE/Ag-treated group.

observed by $\mathrm{H} \& \mathrm{E}$ and toluidine blue staining (Figures $5(\mathrm{~d})$ and 5(e)). H\&E staining confirmed the infiltration of inflammatory cells in the PCA-induced mice. The administration of SIE at doses of 250 and $500 \mathrm{mg} / \mathrm{kg}$ inhibited edema and inflammatory response by histopathological and morphometric analysis of ear sections. Furthermore, the administration of SIE at a dose of $500 \mathrm{mg} / \mathrm{kg}$ significantly decreased the numbers of infiltrating eosinophils. Toluidine blue staining confirmed that mast cells were elevated in the control and IgE/Ag groups. Application of SIE extract treatment group reduced the mast cell numbers, and application of Dex group significantly inhibited mast cell infiltration into ear tissues (Figure 5(c)). These data indicated that SIE may inhibit IgE mediated skin pruritus by down-regulating mast cell activation.

\section{Discussion}

Mast cells are key effector cells in FceRI-mediated allergic responses and can secrete inflammatory mediators, cytokines, growth factors, chemokines, leukotrienes, and hypersensitive factors that activate the immune system upon stimulation by an FceRI-mediated allergic reaction $[14,15]$. 
In the present study, we found that SIE inhibited the degranulation process and production of proinflammatory mediators, such as TNF- $\alpha$, IL-4, IL-6, histamine, and PGD2, on FceRI-mediated allergic reactions in RBL-2H3 mast cells. To elucidate the underlying mechanism, we evaluated the control of antiallergic effects and the expression of FceRI signaling-related genes known to influence the concentrations of proinflammatory mediators.

FceRI on the surface of mast cells consists of $\alpha$-, $\beta$-, and $\gamma$ subunits. When allergens are cross-linked with $\operatorname{IgE}$, the receptor is phosphorylated by Src kinase, which is bound to the $\beta$-subunit, to initiate intracellular signaling [16]. In addition, the $\beta$ - and $\gamma$-subunits phosphorylate the immunoreceptor tyrosine-based activation motif (ITAM) via Lyn kinase, which is bound to the receptor [17]. The phosphorylated ITAM provides a binding site for Syk kinase that plays an important role in cell activation; ITAM activates Syk kinase and then induces activation of the lower signaling substance [18]. In the early stage of mast cell activation by the antigen, Syk, which is the most important signal transduction protein, activates various signaling substances, such as PLC $\gamma$ and protein kinase C [19].

Lyn/Syk activation induces stimulation of MAPKs, which are involved in the production of proinflammatory mediators [20]. MAPK signaling plays an essential role in regulating the transcriptional activity of various cytokine genes in mast cells and is thus a major mechanism of treatment of allergic inflammation [21]. To elucidate the MAPK pathway of action of SIE on FceRI-mediated allergic reactions in mast cells, we tested the effects of SIE on MAPK activation. Treatment with SIE reduces the phosphorylation of MAPK pathways, including ERK, JNK, and MEK1/2 genes in $\mathrm{Ag} / \mathrm{IgE}$-mediated RBL-2H3 mast cells. Additionally, it was found that SIE inhibited the phosphorylation of Akt and $\mathrm{IkB} \alpha$ by Lyn/Syk activation [22]. These observations indicate that Lyn/Syk activation is essential for the degranulation signal transduction.

Next, we found that SIE inhibited COX-2 and CPLA2 expressions and reduced the levels of the PGD2 products, which are enhanced in the activated immune cells including mast cells. COX-2 and cPLA2 are pivotal enzymes for the production of proinflammatory lipid mediators and in the metabolism of arachidonic acid associated with allergic actions [13]. PGD2 is the major arachidonic acid metabolite secreted by mast cells and is known to be produced in response to allergic inflammation [23]. Transgenic mice overexpressing PGD synthase, with a resultant overproduction of PGD2, develop inflammation and Th2 cytokine response following allergen sensitization and exposure [24]. These findings suggest that SIE reduces FceRI-mediated allergic reactions through the suppression of cPLA2 activation and inhibition of COX-2 activity.

Finally, we examined how SIE suppresses IgE-mediated PCA in mice. PCA is characterized by an immediate skin reaction at a localized IgE-mediated allergic response in vivo, typically with increased vascular leakage in the skin that can be assessed by an intravenous injection of Evans blue [25]. In vivo, PCA can be identified based on ear skin color and the number of mast cells in the allergic site at the ears.
Consistent with in vitro findings, SIE successfully reduced allergic inflammatory responses in the PCA-induced mice. This result suggested that SIE inhibits IgE-mediated allergy responses by downregulating mast cell activation. Research based on natural products is associated with the development of complex drugs that influence multiple targets simultaneously, which may be superior in controlling complex disease systems, have lower drug resistance, and are standards of care in numerous important therapies.

\section{Conclusions}

This study showed the antiallergic effects of SIE against FceRI-mediated mast cell activation through the downregulation of FceRI and arachidonate expression, which might cause inhibition of degranulation in RBL-2H3 mast cells and antigen-IgE-mediated PCA reactions. Inhibition of the degranulation process results in reduced production of allergen mediators, such as histamine, TNF- $\alpha$, IL-4, IL-6, and $\mathrm{PGD}_{2}$, caused by $\mathrm{Ag} / \mathrm{IgE}$ interaction. These results indicate that SIE could be a beneficial treatment for allergy-related diseases.

\section{Data Availability}

The data is not available. The data that has been used is confidential.

\section{Conflicts of Interest}

The authors declare no conflict of interest.

\section{Authors' Contributions}

K.I.P. developed the study design and revised the manuscript. H.J.D. participated in the study design, performed the experiments, analyzed the data, and wrote the draft manuscript. T.W.O. performed the experiments and analyzed the data. All authors read and approved the final manuscript.

\section{Acknowledgments}

This work was supported by a grant (no. KSN1812102) from the Korea Institute of Oriental Medicine funded by the Ministry of Education, Science and Technology (MEST), Republic of Korea.

\section{Supplementary Materials}

Method S1: chemicals and reagents. Method S2: HPLC analysis. Results S1: HPLC analysis of SIE. Figure S1: HPLC-DAD chromatograms. (Supplementary Materials)

\section{References}

[1] M. Krystel-Whittemore, K. N. Dileepan, and J. G. Wood, "Mast cell: a multi-functional master cell," Frontiers in Immunology, vol. 6, p. 620, 2016.

[2] K. Amin, "The role of mast cells in allergic inflammation," Respiratory Medicine, vol. 106, no. 1, pp. 9-14, 2012. 
[3] T. C. Theoharides and D. Kalogeromitros, "The critical role of mast cells in allergy and inflammation," Annals of the New York Academy of Sciences, vol. 1088, no. 1, pp. 78-99, 2006.

[4] A. M. Gilfillan, H. Kado-Fong, G. A. Wiggan, J. Hakimi, U. Kent, and J. P. Kochan, "Conservation of signal transduction mechanisms via the human Fc epsilon RI alpha after transfection into a rat mast cell line, RBL 2H3," The Journal of Immunology, vol. 149, no. 7, pp. 2445-2451, 1992.

[5] F. Marchand, S. Mecheri, L. Guilloux, B. Iannascoli, A. Weyer, and U. Blank, "Human serum IgE-mediated mast cell degranulation shows poor correlation to allergen-specific IgE content," Allergy, vol. 58, no. 10, pp. 1037-1043, 2003.

[6] W. Wang, Q. Zhou, L. Liu, and K. Zou, "Anti-allergic activity of emodin on IgE-mediated activation in RBL-2H3 cells," Pharmacological Reports, vol. 64, no. 5, pp. 1216-1222, 2012.

[7] S. O. Nwozo, Y. T. Lewis, and B. E. Oyinloye, "The effects of Piper Guineense versus Sesamum Indicum aqueous extracts on lipid metabolism and antioxidants in hypercholesterolemic rats," Iranian Journal of Medical Sciences, vol. 42, no. 5, pp. 449-456, 2017.

[8] D. Z. Hsu, Y. H. Li, S. P. Chien, and M. Y. Liu, "Effects of sesame oil on oxidative stress and hepatic injury after cecal ligation and puncture in rats," Shock, vol. 21, no. 5, pp. 466469, 2004.

[9] Y. M. Hu, H. Wang, W. C. Ye, and S. X. Zhao, "Flavones from flowers of Sesamum indicum," Zhongguo Zhong Yao Za Zhi, vol. 32, no. 7, pp. 603-605, 2007.

[10] Z. Liu, N. M. Saarinen, and L. U. Thompson, "Sesamin is one of the major precursors of mammalian lignans in sesame seed (Sesamum indicum) as observed in vitro and in rats," The Journal of Nutrition, vol. 136, no. 4, pp. 906-912, 2006.

[11] H. Mastuda, T. Morikawa, K. Ueda, H. Managi, and M. Yoshikawa, "Structural requirements of flavonoids for inhibition of antigen-induced degranulation, TNF- $\alpha$ and IL-4 production from RBL-2H3 cells," Bioorganic \& Medicinal Chemistry, vol. 10, no. 10, pp. 3123-3128, 2002.

[12] H. J. Do, T. W. Oh, J. H. Yang, K. I. Park, and J. Y. Ma, “Davallia mariesii Moore improves FceRI-mediated allergic responses in the rat basophilic leukemia mast cell line RBL-2H3 and passive cutaneous anaphylaxis in mice," Mediators of Inflammation, vol. 2017, Article ID 8701650, 9 pages, 2017.

[13] I. T. Lee, C. W. Lee, W. H. Tung et al., "Cooperation of TLR2 with MyD88, PI3K, and Rac1 in lipoteichoic acid-induced cPLA 2 /COX-2-dependent airway inflammatory responses," The American Journal of Pathology, vol. 176, no. 4, pp. 16711684, 2010.

[14] S. J. Galli, J. R. Gordon, and B. K. Wershil, "Cytokine production by mast cells and basophils," Current Opinion in Immunology, vol. 3, no. 6, pp. 865-873, 1991.

[15] J. Kalesnikoff and S. J. Galli, "New developments in mast cell biology," Nature Immunology, vol. 9, no. 11, pp. 1215-1223, 2008.

[16] J. P. Kinet, "The high-affinity IgE receptor (FceRI): from physiology to pathology," Annual Review of Immunology, vol. 17, no. 1, pp. 931-972, 1999.

[17] R. Siraganian, "Mast cell signal transduction from the highaffinity IgE receptor," Current Opinion in Immunology, vol. 15, no. 6, pp. 639-646, 2003.

[18] M. Turner, E. Schweighoffer, F. Colucci, J. P. Di Santo, and V. L. Tybulewicz, "Tyrosine kinase SYK: essential functions for immunoreceptor signalling," Immunology Today, vol. 21, no. 3, pp. $148-154,2000$.
[19] C. Tkaczyk, M. A. Beaven, S. M. Brachman, D. D. Metcalfe, and A. M. Gilfillan, "The phospholipase $C \gamma_{1}$-dependent pathway of FceRI-mediated mast cell activation is regulated independently of phosphatidylinositol 3-kinase," The Journal of Biological Chemistry, vol. 278, no. 48, pp. 48474-48484, 2003.

[20] T. Hirano, S. Higa, J. Arimitsu et al., "Luteolin, a flavonoid, inhibits AP-1 activation by basophils," Biochemical and Biophysical Research Communications, vol. 340, no. 1, pp. 1-7, 2006.

[21] T. S. Vo, C. S. Kong, and S. K. Kim, "Inhibitory effects of chitooligosaccharides on degranulation and cytokine generation in rat basophilic leukemia RBL-2H3 cells," Carbohydrate Polymers, vol. 84, no. 1, pp. 649-655, 2011.

[22] J. Kitaura, K. Asai, M. Maeda-Yamamoto, Y. Kawakami, U. Kikkawa, and T. Kawakami, "Akt-dependent cytokine production in mast cells," The Journal of Experimental Medicine, vol. 192, no. 5, pp. 729-740, 2000.

[23] M. A. Carey, D. R. Germolec, R. Langenbach, and D. C. Zeldin, "Cyclooxygenase enzymes in allergic inflammation and asthma," Prostaglandins, Leukotrienes, and Essential Fatty Acids, vol. 69, no. 2-3, pp. 157-162, 2003.

[24] A. K. Mandal, Z. Zhang, R. Ray et al., "Uteroglobin represses allergen-induced inflammatory response by blocking PGD2 receptor-mediated functions," The Journal of Experimental Medicine, vol. 199, no. 10, pp. 1317-1330, 2004.

[25] S. H. Lee, H. J. Shin, D. Y. Kim et al., "Streptochlorin suppresses allergic dermatitis and mast cell activation via regulation of Lyn/Fyn and Syk signaling pathways in cellular and mouse models," PLoS One, vol. 8, no. 9, 2013. 


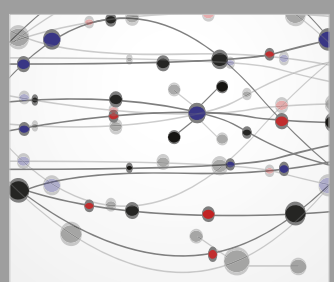

The Scientific World Journal
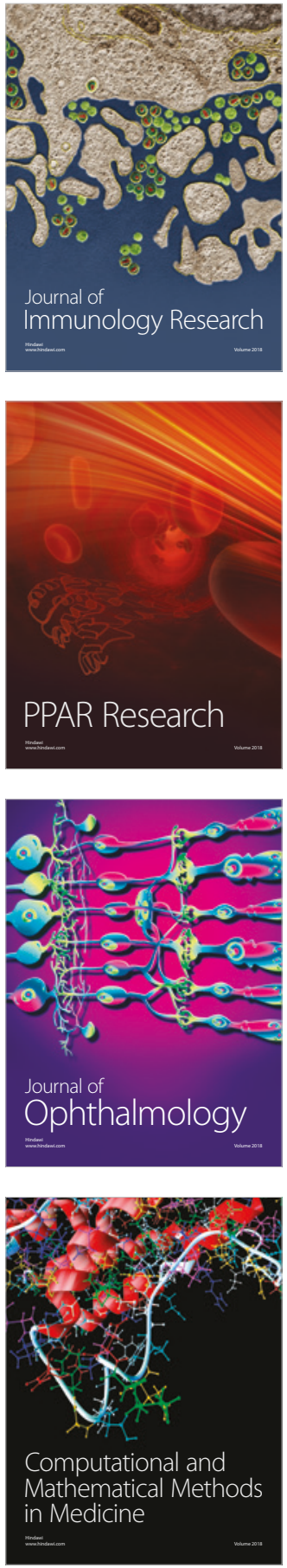

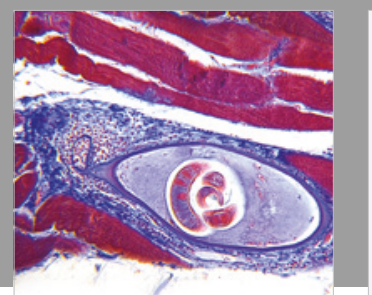

Gastroenterology Research and Practice

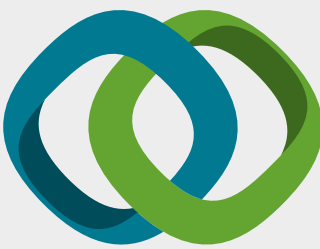

\section{Hindawi}

Submit your manuscripts at

www.hindawi.com
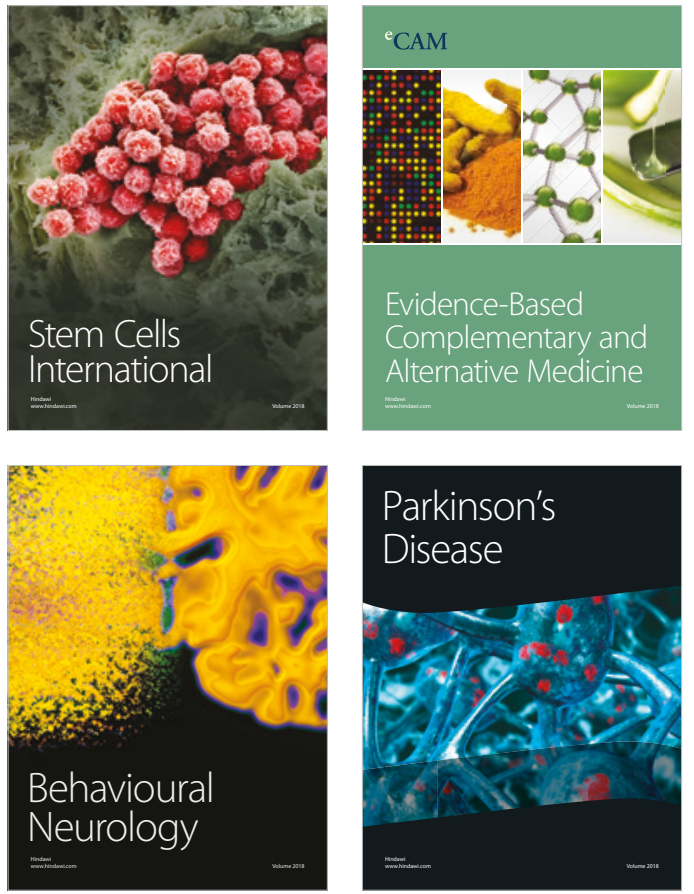

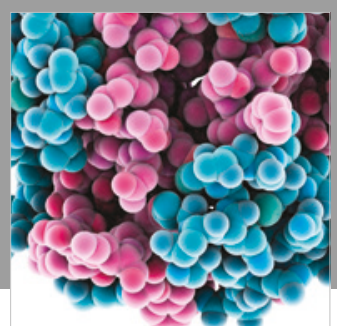

ournal of

Diabetes Research

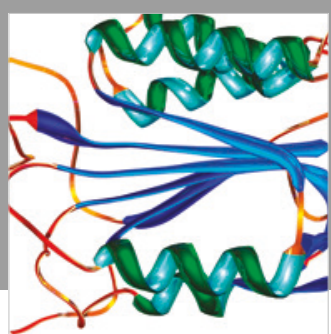

Disease Markers
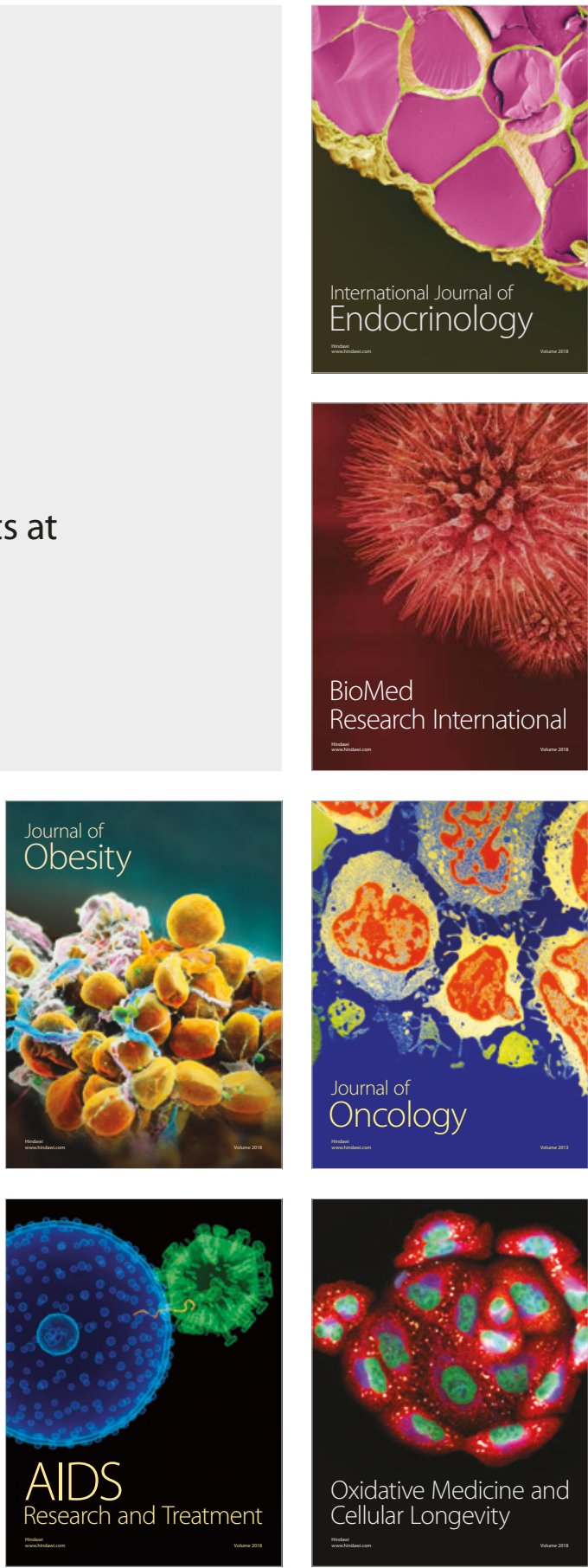